\title{
Increasing Learning Potential in Entry Level Nutrition Students through Online Tutorial
}

\author{
April Litchford $^{1} \&$ Heidi Wengreen ${ }^{1}$ \\ ${ }^{1}$ Nutrition, Dietetics, and Food Science Department, Utah State University, Logan, Utah, USA \\ Correspondence: Heidi Wengreen, Nutrition, Dietetics, and Food Science Department, Utah State University, \\ Logan, Utah, USA. E-mail: heidi.wengreen@usu.edu
}

Received: October 6, 2015

Accepted: October 28, $2015 \quad$ Online Published: December 21, 2015

doi:10.5539/jedp.v6n1p37

URL: http://dx.doi.org/10.5539/jedp.v6n1p37

\begin{abstract}
The objective of this study was to assess whether implementation of an online tutoring program, MasteringNutrition $\odot$, would produce measurable gains in student learning outcomes. Research conducted by Pearson $($, the creator of MasteringNutrition $\mathbb{C}$, indicates that the inclusion of Mastering $\odot$ tutoring programs into existing courses has the ability to increase student performance on assessments and total course grades. Students of a general education, nutrition course were invited to participate in this study: spring of 2013 (no Mastering; $\mathrm{n}=182$ ), fall of 2013 (Mastering; $\mathrm{n}=86$ ), and spring of 2014 (Mastering; $\mathrm{n}=410$ ). NDFS 1020 is an introductory nutrition course taught in a blended style. Course structure includes course lectures (60\% of instruction time) and online assignments ( $40 \%$ of instruction time), Mastering $($ ) is included as part of required assignments. Learning outcome progress was measured by questions on a pre-semester quiz, final exam, and posttest six months after course completion. Assessments measured student progress based on course learning objectives. Results of statistical tests reported no significant difference in test scores for each group over time. Students who scored lower than the mean on the pretest and used the Mastering $(\subset$ program demonstrated greater improvements in final and posttest scores compared to those who scored higher than the mean on the pretest $(\mathrm{p}=<.001)$. Implementation of online tutoring program did not significantly improve overall student outcomes. Online tutorial programs may be helpful for students who are enrolled in courses where they have little prior knowledge of subject matter.
\end{abstract}

Keywords: nutrition education, online tutoring, teaching pedagogy

\section{Instructional Pedagogy}

\subsection{Effectiveness of Instructional Techniques}

Various instructional methods have the ability to change the amount of knowledge acquired by students in collegiate/university courses. The history of education is riddled with large amounts of research concerning the effectiveness of various instructional techniques (Jennings, 2012; Ormrod, 2012). Traditionally, instructional methods employed at a collegiate level have consisted largely of lectures. A major advantage associated with lecture based learning is the ability to present a large amount of information quickly to a large audience (Jennings, 2012). The largest disadvantages of lecture based teaching lies in the passive nature of information transfer, as students do little more than listen to information instead of discovering information (Jennings, 2012; Teater, 2011). Studies have concluded that active participation in the classroom enhances student comprehension and subsequent retention of subject matter (Teater, 2011). This idea of active learning has sparked a revolution of traditional teaching methods. Various innovative educational theories and instructional methods have been developed in an attempt to increase the effectiveness of information transfer from instructor to student (Jennings, 2012). Scientific evidence supports the use of several teaching methods, the use of these methods is becoming common in collegiate classrooms worldwide (Yang et al., 2005; Tanner, 2012; Kuruganti et al., 2012).

A few of these innovative teaching methods include use of the Socratic Method, an understanding of metacognition or self-directed learning, and Problem Based Learning (PBL) (Yang et al., 2005; Tanner, 2012; Kuruganti et al., 2012). These techniques encourage students to be actively involved in learning, which will help increase learning retention of subject matter (Yang et al., 2005; Tanner, 2012). 


\subsection{MasteringNutrition $(\bigcirc$ Online Tutoring Program}

The course discussed in this study is designed around the instructional techniques mentioned above. The course is taught in a blended format; students attend one lecture weekly and then complete assignments online at their own pace. The course includes an online tutoring program called MasteringNutrition $($ (Mastering $($ ). MasteringNutrition $(\mathcal{C}$ was developed by Pearson, a large publishing company. Pearson claims that the Mastering(C) platforms have the ability to increase student performance in courses of various disciplines (Aspey, 2010; Pearson, 2014). The nature of the blended course format and the Mastering $\odot$ program combines different teaching pedagogy into one course design. The instructor uses a lecture/discussion format to enhance student understanding of course material, the Mastery® program incorporates use of Socratic questioning, self-directed learning, and PBL to further enhance understanding of the same concepts.

The Mastery@ program uses questioning in the Socratic pattern to create differences in the level of active learning, sometimes termed critical thinking, experienced by students (Teodoro et al., 2011; Yang, 2005). Several studies have investigated the success of this type of questioning to increase critical thinking skills (Yang, 2005; Tofade et al., 2013). Mastery $\odot$ also uses self-directed learning to actively engage students in the learning process. The program permits students to answer questions multiple times. This helps students to discover which concepts they do not fully understand, enhancing individual use of metacognition (Tanner, 2012; Sandi-Urena et al., 2011). PBL also plays a strong role in the Mastery $\mathcal{C}$ assignments, the program will give students the ability to solve problems as part of an assignment activity. Research has shown that using PBL can increase overall understanding of course material because it requires students to think at a deeper level and to remain actively engaged in the learning process (Kuruganti, 2012; McDonald, 2013). Not only can PBL create better understanding of concepts, it is also a preferred teaching method by many students (Boone \& McCoy, 2013). A recent study reported that students rated a PBL structured course higher than a lecture based course on a preference scale (Boone \& McCoy, 2013).

\subsection{Learning Retention}

Lasting knowledge is sometimes defined as learning retention. Retention of knowledge gain is a concern of many instructors in various fields of study (Crosling \& Heagney, 2009). A key to enhanced learning retention is student engagement in subject matter (Crosling \& Heagney, 2009). Student engagement has been discussed as the single most important indicator of course outcomes for individual students (Crosling \& Heagney, 2009). A recent study explored the use of active learning engagement to assess perceived learning retention (Smith \& Cardaciotto, 2011). The active learning groups formed during the study reported significant differences in learning retention $(\mathrm{p}=<.001)$ when compared to the course review groups (Smith \& Cardaciotto, 2011). Other studies have conducted similar investigations with similar results (Rosegard \& Wilson, 2013; Cherney, 2009).

Mastery $\odot$ is a comprehensive teaching tool that reinforces concepts discussed in course readings, assignments, and lectures. This program is intended to create an active, engaging learning experience for students. The objective of this study is to measure increased learning retention in students that used Mastery $\odot$ as part of the course design.

\section{Methods}

Students ( $\mathrm{n}=496)$ enrolled in an introductory nutrition course were assigned to use an online tutoring program (MasteringNutrition(C) as part of the graded component of a blended format course in general nutrition (NDFS 1020). Information was collected over two 15 week semesters ( $n=86$ fall semester, $n=410$ spring 2014 semester). Prior to study initiation, approval of procedures and informed consent was granted from the Utah State University Review Board. Students were informed of the study during the first class lecture and were given contact information if they desired more details concerning the study. Each student was given the opportunity to participate in a pre-course survey, if they participated they were awarded ten points extra credit in the course.

The pre-survey included ten core knowledge questions (Table 1). Each question was written to test student understanding of basic nutrition concepts. Each nutrition concept assessed corresponded to a specific learning objective designed for the NDFS 1020 course. The questions were asked as multiple choice questions. The data from the pre-survey was collected via an online survey format through Canvas. 
Table 1. Learning objectives used to categorize questions used for pre, final, and posttest (Actual questions used for testing are organized under specific objectives.)

IDEA objective 1a: Gain FACTUAL KNOWLEDGE (terminology, classifications, methods, trends). Describe the digestion and metabolism of the energy nutrients (carbohydrates, lipids, protein).

Once absorbed, all monosaccharides are converted to by the liver.

In general, B vitamins function as and are needed for metabolism and energy production.

IDEA objective 1b: Gain FACTUAL KNOWLEDGE (terminology, classifications, methods, trends). Identify the nutrients needed to maintain health and body function. Be familiar with symptoms of nutrient deficiencies and toxicities. Recognize food sources for each nutrient.

Which of the following represent a significant source of vitamin $\mathrm{E}$ in the diet?

Adequate fluid consumption, carbohydrate counting, restricted intake of simple sugars, daily glucose testing, and weight management are all recommended measures for ?

IDEA objective 2a: Learn FUNDAMENTAL PRINCIPLES, generalizations, or theories. Discuss the role of nutrition in relation to health and the prevention of chronic disease.

Which of the following statements concerning weight management and fitness is FALSE?

Which of the following is NOT a recommendation for healthy weight loss?

IDEA objective 3a: Learn to APPLY COURSE MATERIAL (to improve thinking, problem solving, and decision-making). Describe what constitutes a sustainable food system and understand the effects of food policy and production on consumers.

Compared to food that's been transported, locally grown foods

IDEA objective 3c: Learn to APPLY COURSE MATERIAL (to improve thinking, problem solving, and decision-making). Evaluate food quality based on food labeling, nutrition labeling, and food safety practices.

You are trying to decide what kind of soup to have for dinner. You have discovered that your diet is often low in iron (a mineral that's required for proper oxygen transport in the body). Which of the following soups would give you the most iron per kcal? Bean Soup $=3.08 \mathrm{mg}$ Iron (191 kcals) Chicken Noodle $=1.34 \mathrm{mg}$ Iron (117 kcals) Tomato Soup $=1.81 \mathrm{mg}$ Iron (161 kcals) Vegetable Soup $=2.45 \mathrm{mg}$ Iron (96 kcals)

The following nutrients are listed in this order on a food label: enriched wheat flour (flour, niacin, reduced iron, thiamine mononitrate, riboflavin, folic acid), partially hydrogenated vegetable shortening, salt, sodium bicarbonate, malted barley flour, yeast. What can you conclude?

IDEA objective 11b: Learn to ANALYZE \& CRITICALLY EVALUATE ideas, arguments, and points of view. Differentiate between credible, science-based sources of nutrition information and unreliable sources. Research findings and results that are are the most reliable

Students were assigned MasteringNutrition $\odot$ activities/quizzes on a weekly basis. These weekly assignments were estimated to take the average student approximately 30-45 minutes to complete, however the activities were not timed. This allowed students to finish the assignments at their own pace. Fourteen Mastery assignments were available for students to complete during each semester. The highest twelve scores were used in the computation of grades for the semester and accounted for $12 \%$ of the students total grade. 
The same questions used in the pre-survey were incorporated into the final exam for the course. These questions were scored as part of the final exam; however students were not informed prior to the final exam. The questions on the final exam were not voluntary as they addressed key concepts and counted towards their final exam score. The numbers of final assessment responses collected by group are presented in Table 2 .

Table 2. Total responses collected for pretest, final test, and posttest

\begin{tabular}{llll}
\hline & Control & Mastery fall 2013 & Mastery spring 2014 \\
\hline Students enrolled per & 185 & 95 & 408 \\
Semester & & & \\
Pretest & NA $^{1}$ & 88 & 393 \\
Final test & 183 & 85 & 306 \\
Posttest & 96 & 65 & 130 \\
Posttest \% response $^{2}$ & 52 & 68 & 32 \\
\hline
\end{tabular}

In order to assess learning retention, students were asked to participate in a third survey conducted 4-6 months after completing NDFS 1020. Preferred email addresses for each enrolled student were obtained from past course rosters. An email was sent (Table 3) to these addresses inviting students to participate in a posttest survey that included the same core nutrition questions. As an incentive, each participant was entered into a drawing with the potential to win prizes. The control group (spring 2013) was the first to be offered the post survey and the following prizes were available: $1-\$ 100.00$ gift card, 2 -sweatshirts, and 25 ice cream coupons. The treatment groups (fall 2013 and spring 2014) were offered $2-\$ 100.00$ gift cards as their prizes. The total responses collected are presented in Table 2 .

Table 3. Sample post-test email

Dear Student,

You have been selected to participate in a research study that focuses on nutrition education. This email is being sent to you because you completed NDFS 1020 (The Science \& Application of Human Nutrition) at Utah State University in the fall of 2013.

To participate, click on the link below and complete the survey. The survey should only take 5-10 minutes to complete.

Once you have completed the quiz you may enter to win one of two $\$ 100$ Best Buy Gift Cards! The deadline for participation is Monday March $31^{\text {st }}$ so don' $t$ delay.

After responses were collected, each respondent was given a number in order of submission. These numbers were entered into an online random sequence generator. The first two numbers were contacted through information obtained from the survey. The students were contacted within a week of survey closure; each winner was given one week to pick up their prize. The results of the post-test survey were analyzed and compared to the collected data from the pre-test and final exam responses.

Data for the control group was generated from existing student test results of the spring 2013 semester of NDFS 1020. This semester did not use Mastering $\odot$ assignments as part of the course. Two sections of this course took their final exam online. Questions that were similar to the core nutrition knowledge questions used in the assessments described above were selected from the final exam questions recorded. These questions addressed the same learning objectives but were worded differently than the posttest questions used for the intervention groups. The questions that differ are listed in Table 4. Pretest information was not available for the spring 2013 control group because a pretest was not administered to these students as part of the course design. 
Table 4. Learning objectives used to categorize questions used for pre, final, and posttest (Actual questions used for testing are organized under specific objectives.)

IDEA objective 1a: Gain FACTUAL KNOWLEDGE (terminology, classifications, methods, trends). Describe the digestion and metabolism of the energy nutrients (carbohydrates, lipids, protein).

All nutrients that provide energy are converted into before directly entering the TCA cycle. This is often called the "crossroads of metabolism" or the "gateway" molecule.

Based on the Acceptable Macronutrient Distribution Range (AMDR) for PROTEIN, how many kilocalories should a person consume from protein if his/her Estimated Energy Requirement (EER) is 2,400 kilocalories?

IDEA objective 1b: Gain FACTUAL KNOWLEDGE (terminology, classifications, methods, trends). Identify the nutrients needed to maintain health and body function. Be familiar with symptoms of nutrient deficiencies and toxicities. Recognize food sources for each nutrient

Which of the following foods would be the POOREST source of folate?

\section{IDEA objective 2a: Learn FUNDAMENTAL PRINCIPLES, generalizations, or theories. Discuss the role of} nutrition in relation to health and the prevention of chronic disease.

Even a moderate reduction in body weight $(5-10 \%)$ can improve the health of overweight individuals. (T/F) Suppose your neighbor gets a blood lipid profile from their physician. If their HDL cholesterol is low and LDL cholesterol levels are high, their doctor (or dietitian) would most likely recommend that they increase fats and to decrease fats in their diet.

Each student that completed NDFS 1020 in the spring of 2013 was asked to participate in a posttest survey administered using the same method described above. They were asked the same questions as the Mastering( $)$ groups. Responses were analyzed and used for comparison of Mastering $\odot$ groups to the control group (Table 2). All of the survey/test results for both Mastering $\odot$ groups were compared to the results of the control group.

Data for Mastering $\odot$ groups were collected over two consecutive semesters. Data for the pretest given to the Mastering@ groups was gathered using an online testing forum administered through Canvas. This data was organized into a spreadsheet and entered into a statistical analysis program. (SPSS) Data for the final test for the Mastering $\odot$ groups was gathered from scantron results. Targeted questions were identified from test results and input by hand into a spreadsheet. This data was then entered into SPSS. Data for the final test for the control group was gathered from recorded online test submission; the test was given through Canvas. Questions were identified that addressed course learning objectives and responses were recorded into a spreadsheet. This spreadsheet was then entered into SPSS.

Data for the posttests was gathered through two online survey programs. Data for the control group (spring 2013) were gathered in Survey MonkeyC. This data was downloaded into a spreadsheet and entered into SPSS. Data for the Mastering $(\mathcal{C}$ groups was gathered using Qualtrics $\odot$ surveys. This data was also downloaded into a spreadsheet and entered into SPSS.

\section{Results}

The distributions of assessment scores were examined and all were approximately normally distributed. Descriptive statistics of students by group are provided in Table 5. Results indicated a change in the percent of questions students got correct for each assessment given. Scores from both Mastering $\odot$ groups pretest to final test increased where scores from final test to posttest decreased. The Mastering $\odot$ groups pretest scores were much lower than those recorded for each group's posttest results. 
Table 5. Descriptive statistics for study participants by group

\begin{tabular}{|c|c|c|c|c|}
\hline & $\begin{array}{l}\text { Control } \\
(\mathrm{n}=182)\end{array}$ & $\begin{array}{l}\text { Mastering }(\text { ) } \\
\text { (fall } 13 \mathrm{n}=88 \text { ) }\end{array}$ & $\begin{array}{c}\text { Mastering@ (spring } \\
14 \mathrm{n}=393 \text { ) }\end{array}$ & P-value ${ }^{1}$ \\
\hline Female \% & 74 & 60 & 70 & .087 \\
\hline White $\%$ & 90 & 88 & 87 & .032 \\
\hline $\begin{array}{c}\text { Age } \% 18-24 \text { years } \\
\text { of age }\end{array}$ & 85 & 82 & 87 & $<.001$ \\
\hline Pre-test ${ }^{2}$ & NA & $.50(\mathrm{n}=88)$ & $.51(\mathrm{n}=393)$ & .518 \\
\hline Final test ${ }^{2}$ & $.757(\mathrm{n}=182)$ & $.76(n=85)$ & $.75(n=306)$ & .518 \\
\hline Post test ${ }^{2}$ & $.72(\mathrm{n}=96)$ & $.74(n=93)$ & $.70(n=130)$ & .592 \\
\hline
\end{tabular}

Paired sample t-tests were used to examine differences in assessment scores within each semester, (Table 6) independent of other semesters or the control group. Significant differences were observed in mean sores by test for fall 2013 pretest to posttest $(\mathrm{p}=.003)$. No differences were observed in the fall 2013 final test to posttest $(\mathrm{p}=.071)$, and pre-test to final test $(\mathrm{p}=.194)$. Significant differences in mean scores by test were also observed for spring 2014; pre-test and final test $(\mathrm{p}=<.001)$, the pre-test and posttest $(\mathrm{p}=<.001)$, and the final test and posttest $(\mathrm{p}=.001)$.

Table 6. Paired sample t-test results

\begin{tabular}{cccc}
\hline & Pretest to posttest & Pretest to final test & Final test to posttest \\
\hline \multirow{2}{*}{ Fall 2013} & $\mathrm{p}=.003$ & $\mathrm{p}=.194$ & $\mathrm{p}=.071$ \\
& $(\mathrm{n}=88,93)$ & $(\mathrm{n}=88,85)$ & $(\mathrm{n}=85,93)$ \\
Spring 2014 & $\mathrm{p}=<.001$ & $\mathrm{p}=<.001$ & $\mathrm{p}=.001$ \\
$(\mathrm{n}=393,130)$ & $(\mathrm{n}=393,306)$ & $(\mathrm{n}=306,130)$ \\
\hline
\end{tabular}

A repeated measures analysis was conducted to assess the group by score over time effect between both Mastery groups and the control group. Comparison between Mastering $\odot$ fall 2013 and Mastering $\odot$ spring 2014 were non-significant, $p=.677$. Comparison between both Mastering $\odot$ groups and the control group was non-significant, $\mathrm{p}=.287$. Figure 1 is a graphical representation of the measured effect of each group. Student test scores tended to be highest on the final test and decrease on the posttest. 


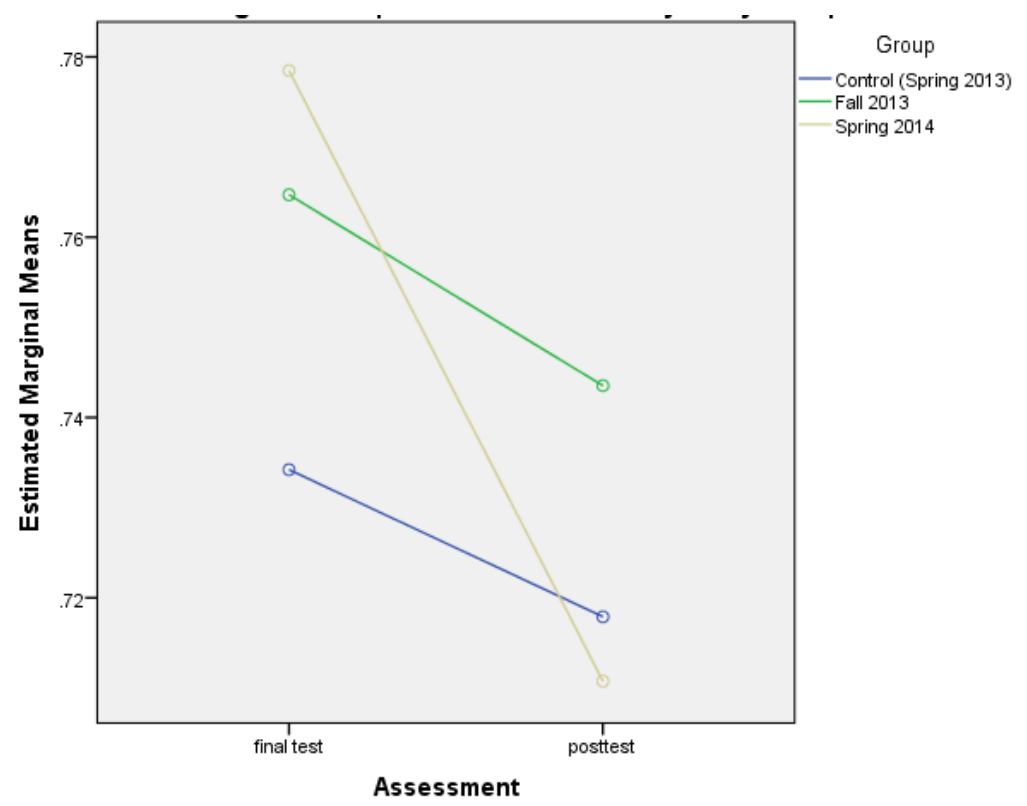

Figure 1. Repeated measures analysis by group

Results of a chi square analysis for categorical variables are presented in Table 5. Age, gender, and ethnicity differed by group, these variables were included as covariates in the repeated measures described above as analysis of covariance. In addition, to examine whether these factors mediated the association between assessment score and group, the interaction term for these covariates and the assessment score over time were included in the model. None of these interaction terms were statistically significant indicating that the effect of score over time did not depend on group assignment, gender, age, instructor, or ethnicity of the study participants. P-values reported include; test scores*instructor .502, test scores*race .186, test scores*age .651, tests scores*gender 333 .

A repeated measures analysis was conducted using a split variable. Participants were divided in to two groups depending on how they scored on the pretest; group one included students that scored above average and group two included the students that scored below average. There was a significant statistical difference in test scores between these groups as well, $p=<.001$. Suggesting that students that used the MasteringNutrition $\odot$ program were able to increase basic nutrition concepts over the duration of the NDFS 1020 course. This increase in basic nutrition knowledge allowed the below average group to demonstrate test scores comparable with the above average group by the end of the course. Figure 2 shows graphically the change in student test scores over time according to group. 


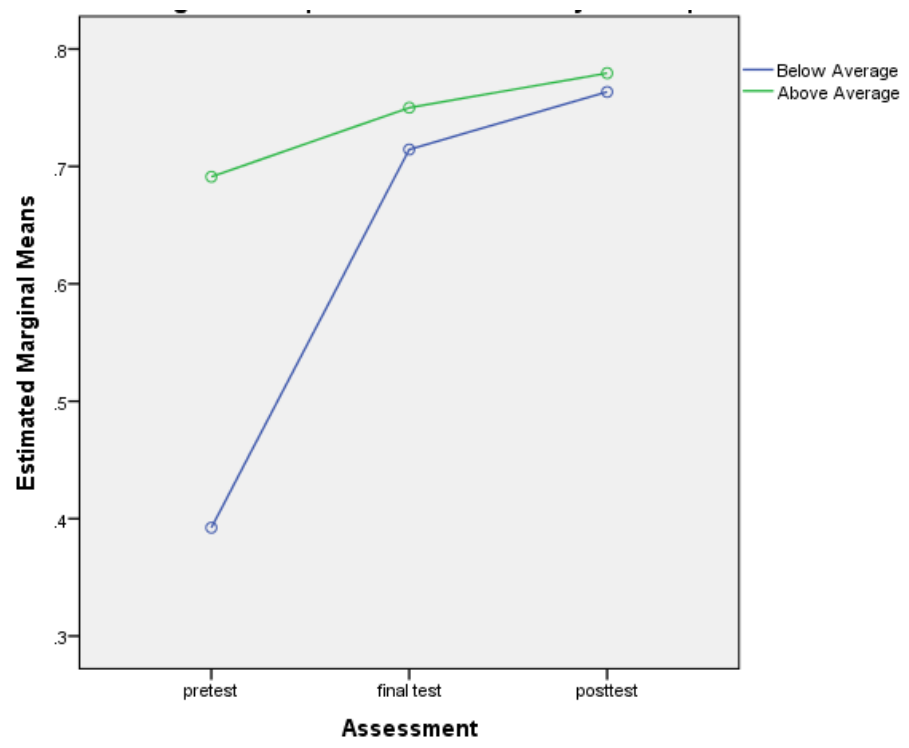

Figure 2. Repeated measures analysis for split variable

\section{Discussion}

MasteringNutrition $(\mathcal{C}$ was not successful in improving individual student outcomes when compared to the control group outcomes in NDFS 1020. The MasteringNutrition $($ ) tutorial was created using similar models previously implemented and tested by several universities across the United Sates (Speckler, 2015). The data presented by Pearson on MasteringBiology $\bigodot$ is the closest comparison available, both biology and nutrition are life sciences, for the MasteringNutrition(C) program. Pearson's white paper discusses nine studies centered on MasteringBiology $\odot$ (Speckler, 2015). Each study reported significant improvements in student scores when Mastering $\odot$ was used as a course supplement (Speckler, 2015). These papers are similar in design to the studies described above, using overall exam and course scores to assess benefit (Rayner, 2008). There is currently no research available that tests MasteringNutrition $(\mathcal{C}$ exclusively.

The evidence of success using Mastering $($ programs has been well documented by Pearson, the results of our study are inconsistent with these results. This can be explained partially by differences in the way that learning was assessed. The studies cited by Pearson used comparisons of overall grades from established courses over several semesters or years. Our study looked at the improvement of students on specific, core knowledge questions, instead of general letter grades or exam averages. We used these core knowledge questions in order to control for students that began the class with little to no knowledge of nutrition concepts.

The results reported in this paper improved in question response from the pretest to the final test; this suggests that student understanding of concepts did improve during the duration of the course. We observed a decrease in student scores from the final test to the posttest given, but the posttest scores were higher than the pretest scores for each Mastering $\odot$ group. This suggests that students did gain and retain conceptual knowledge introduced to them through the NDFS 1020 course. Learning retention was indicated for both Mastery groups and the control group. Posttest scores for all groups were higher than each corresponding pretest scores. There was no difference observed in increased learning retention for the Mastery $\subseteq$ groups when compared to the control groups. This indicates that learning of defined objectives is occurring and being retained, but is not affected by the Mastering activities.

One strength noted by researchers was the effect Mastering $\odot$ had on students that entered the NDFS 1020 course with less knowledge. Students that scored lower on the pretest tended to gain more knowledge during the course when they used the Mastering( $\odot$ program (Figure 2). In fact, below average pretest scores improved to be comparable to the above average student's final exam scores. One benefit of the Mastering $\odot$ tutorials may be the ability to help students gain fundamental nutrition knowledge they may be lacking.

The population of our sample was largely young (18-25 years of age), white, females. This creates a bias in our sampling and limits our ability to make general conclusions regarding older students and male students. Potential bias of categorical variables was significant when chi square analysis was conducted. In order to address the 
potential for statistical bias in our sample, a repeated measures analysis was conducted. The results of the repeated measures analysis indicated non-significance across all variables. Analysis did not suggest that any statistical bias existed in our sample.

The percent student response rate for each posttest given was lower for each Mastering $\odot$ semester than the control group. Due to the small sample size of posttest responses in Mastering $(\mathcal{C}$ groups there may be some conditions of bias in the results. When data was analyzed to discover potential bias, it was noted that students that earned a high score in the course overall were more likely to take the posttest. We attempted to get a larger sample of posttest responses for the Mastery spring 2014 group by extending the length of the availability of the posttest. This was not successful in generating a higher response rate. However, the population of students that took the posttest were not statistically different in a repeated measure analysis $(\mathrm{p}=.71)$.

Some problems with data collection were experienced over the course of this study. A change in how the final exam was administered in NDFS 1020 caused pertinent data to be lost. Final exams had previously been given through an online format; administrators changed this to a paper base format where students recorded responses on a scantron sheet. This new format created difficulty in gathering final exam data for each Mastering $\odot$ group. Three sections of fall NDFS 1020 final exam data were unavailable due to data collection errors on scantrons. This explains why the amount of posttest responses collected was larger than the final exam scores used for data analysis. Also, some data was missing from final exam responses for spring 2014. However, the amount lost was minimal when compared to losses seen for the fall 2013 group.

\section{Implications for Research and Practice}

The implementation of Mastering $\odot$ into NDFS 1020 did not create the effect expected by course administrators and researchers. Mastering $($ ) did not increase student conceptual understanding according to our research. Review of conducted analysis did reveal that MasteringNutrition $\mathbb{C}$ could be a valuable resource for students that lack basic nutrition concept understanding. The Matery $\odot$ program has the potential to help entry level students learn basic nutrition concepts quickly in order to facilitate understanding of more complex concepts. Continued use of MasteringNutrition $(\mathcal{C}$ is recommended to provide a successful learning experience for all students regardless of prior experience and knowledge.

\section{References}

Aspey, S. (2010). Demand grows for Pearson's online learning programs. Ednetnews Online.

Boone, C., \& McCoy, L. (2013). Problem-based learning and student attitudes in mathematics (pp. 7-12). Wake Forest University, Department of Education Research Digest.

Crosling, G., \& Heagney, M. (2009). Improving teaching and learning. Australia University Review, 51, 9-18.

Cherney, I. (2009). The effects of active learning on students' memories for course content. Active Learn High Education, 9, 152-171. http://dx.doi.org/10.1177/1469787408090841

Jennings, M. (2012). In defense of the sage on the stage: Escaping from the "sorcery" of learning styles and helping students learn how to learn. Journal of Legal Stud Education, 29, 191-237. http://dx.doi.org/10.1111/j.1744-1722.2012.01105.x

Kuruganti, U., Needham, T., \& Zundel P. (2012). Patterns and rates of learning in two problem-based learning courses using outcome based assessment and elaboration theory. Canadian Journal of Scholarly Teaching Learning, 3, 1-17. http://dx.doi.org/10.5206/cjsotl-rcacea.2012.1.4

McDonald, B. (2013). Evaluation instruments used in problem-based learning. ERIC Online, 1-20.

Ormrod, J. E. (2012). Human Learning (6th ed.). Boston, MA: Pearson.

Pearson. (2014). Mastering Health/Mastering Nutrition. Retrieved from http://www.pearsonmylabandmastering.com

Rayner, G. (2008). Evaluation and student perception of "MasteringBiology" as a learning and formative assessment tool in a first year Biology subject. Sch. Biolog. Sci. Retrieved from http://www.unisa.edu.au/ATNAssessment08/

Rayner, G. (2008). Using "mastering biology" to formatively improve student engagement and learning in first year biology. Sch. Biolog. Sci. 
Rosegard, E., \& Wilson, J. (2013). Capturing students' attention: An empirical study. Journal of the Scholar of Teaching and Learning, 13, 1-20.

Sandi-Urena, S., Cooper, M. M., \& Stevens, R. H. (2011). Enhancement of metacognition use and awareness by means of a collaborative intervention. International Journal of Science Education, 33, 323-340. http://dx.doi.org/10.1080/09500690903452922

Smith, V. C., \& Cardaciotto, L. (2011). Is active learning like broccoli? Student perceptions of active learning in large lecture classes. Journal of the Scholar of Teaching and Learning, 1, 53-61.

Speckler, M. D. (2015). Active learning: Implementation strategies for high impact. Pearson. Retrieved from November 15, 2014, http://www.pearsonmylabandmastering.com

Tanner, K. D. (2012). Promoting student metacognition. CBE Life Science Education, 11, 113-120. http://dx.doi.org/10.1187/cbe.12-03-0033

Teater, B. (2011). Maximizing student learning: A case example of applying teaching and learning theory in social work education. Social Work Education, 30, 571-585. http://dx.doi.org/10.1080/02615479.2010.505262

Teodoro, S. D. et al. (2011). Asking good questions, promoting greater understanding of mathematics through purposeful teacher and student questioning. Canadian Journal of Action Resolution, 12, 18-29.

Tofade, T., Elsner, J., \& Haines, S. T. (2013). Best practice strategies for effective use of questions as a teaching tool. American Journal of Pharmacy Education, 77, 1-9. http://dx.doi.org/10.5688/ajpe777155

Yang, Y. C., Newby, T. J., \& Bill, R. L. (2005). Using Socratic questioning to promote critical thinking skills through asynchronous discussion forums in distance learning environments. American Journal of Distributive Education, 19, 163-181. http://dx.doi.org/10.1207/s15389286ajde1903_4

\section{Copyrights}

Copyright for this article is retained by the author(s), with first publication rights granted to the journal.

This is an open-access article distributed under the terms and conditions of the Creative Commons Attribution license (http://creativecommons.org/licenses/by/3.0/). 